\title{
Aspectos da Nova Economia Institucional na Agroindústria Canavieira no Estado do Paraná
}

\author{
Darcy Jacob Rissardi Júnior \\ (Doutor em Desenvolvimento Regional e Agronegócio pela Universidade Estadual do Oeste do \\ Paraná - UNIOESTE) \\ Pery Francisco Assis Shikida \\ (Doutor em Economia Aplicada pela ESALQ/USP; Professor Associado da UNIOESTE) \\ André Maia Gomes Lages \\ (Doutor em Economia da Indústria e da Tecnologia pela Universidade Federal do Rio de \\ Janeiro. Professor Adjunto da Universidade Federal de Alagoas)
}

\begin{abstract}
Resumo:
O objetivo deste artigo é investigar, a guisa da Nova Economia Institucional, as principais percepções dos dirigentes da agroindústria canavieira no Paraná frente aos desafios ocasionados pela desregulamentação setorial. Como principais resultados, confirmou-se uma maior relevância das regras formais que afetam o desempenho das organizações neste setor. Os contratos e coordenação vertical no setor prevalecem, fato este relacionado com a procura pela redução da incerteza nas relações econômicas. A punição para a quebra contratual aplica-se, quando isto ocorre, ao fornecedor de insumos ou matéria-prima.
\end{abstract}

Palavras-Chave: Nova Economia Institucional, agroindústria canavieira, Paraná.

\begin{abstract}
:
The aim of this paper is to investigate the main perceptions of the leaders of the sugar cane agroindustry in Paraná State, using the New Institutional Economics, in the context of the challenges caused by the sector of regulation. As principal results, it was confirmed the greater relevance of formal rules that affect the performance of organizations in the sector. Contracts and vertical coordination prevail, this fact is related to the search for reduction of uncertainty in economic relations. The punishment for breaking the contract is applied, when it occurs, the supplier of inputs and raw materials.
\end{abstract}

Keywords: New Institutional Economics, sugarcane agroindustry, Paraná State 


\section{1) INTRODUÇÃO}

As atividades agropecuárias no Paraná desde os seus primórdios foram e ainda são resultantes da boa combinação de seus solos com o clima, e a introdução da cultura canavieira no estado não fugiu a esta regra, embora outros condicionantes tenham sido importantes para o avanço dessa relevante atividade para a questão de segurança alimentar (via produção do açúcar) e para a questão da segurança energética (via produção de etanol e cogeração de energia elétrica) (Secretaria da Agricultura e do Abastecimento - SEAB, 2011; Dahmer-Felício, 2011).

Numa breve perspectiva histórica, segundo Kaefer e Shikida (2000), o Paraná não apresentou influência no ciclo da economia açucareira que vigorou nos primeiros séculos de colonização do Brasil, pois sua tradição inicial focava no setor de subsistência, tropeirismo, extração da erva-mate e madeira. Somente com o desabastecimento de açúcar no Centro-Sul, durante $2^{a}$ Guerra Mundial (1939-1945), é que houve descentralização da produção nacional de cana, açúcar e álcool, propiciando a expansão da agroindústria canavieira em estados sem tradição no setor, sendo o caso paranaense. Contudo, foi com o Programa Nacional do Álcool (Proálcool) que a produção de cana no Paraná avançou consideravelmente. Dados mostram um aumento da área colhida com cana que passou de 57.990 ha em 1980 para 140.772 ha em 1986, ultrapassando os 300.000 ha a partir de meados dos anos 1990. O Paraná chegou a ser o $2^{\circ}$ maior produtor de cana do País.

A produção de cana estadual tem acompanhado as vicissitudes da indústria sucroalcooleira, mediante investimentos na ampliação da área de cultivo e no volume de cana produzida, além de elevação da produtividade e da melhoria da qualidade da matéria-prima. Ademais, entre os principais subprodutos derivados da economia canavieira, o bagaço da cana vem sendo destinado à geração de energia calorífera em unidades termoelétricas, além de constituir suplemento para a engorda de animais (Dahmer-Felício, 2011; Tranin, 2014).

A cultura da cana-de-açúcar ocupa $3,74 \%$ da área agricultável do Paraná concentrando-se, sobretudo, nas mesorregiões Norte Central, Norte Pioneiro, Noroeste e Centro-Ocidental. Existem 655 mil hectares plantados no estado e há, ainda, potencial que pode ser ocupado pela cultura canavieira principalmente em áreas de pastagem extensiva. São 30 unidades produtivas em funcionamento, entre usinas e destilarias, que geram cerca de 60.000 empregos diretos (Tranin, 2014). Em termos quantitativos o Paraná produziu, 
na safra 2013/2014, 42,2 milhões de toneladas de cana, 3,0 milhões de toneladas de açúcar e 1,5 bilhão de litros de etanol. Relativamente, estes números qualificam o estado como o 4ํㅡㄹ lugar na produção nacional de cana, $3^{\circ}$ lugar na produção de açúcar e $5^{\circ}$ lugar na produção de etanol, sendo responsável por $6,5 \%$ da produção canavieira, $5,4 \%$ da produção alcooleira e $8,1 \%$ da produção açucareira do País (União da Indústria da Cana-de-Açúcar - UNICA, 2015).

Sabe-se que a agroindústria canavieira, no Brasil de modo geral, experimentou até a década de 1990 um ambiente institucional altamente regulamentado pelo Estado, não possibilitando desta maneira uma maior diferenciação entre as organizações que compunham este sistema agroindustrial, pois todos os seus agentes produtores (especialmente usinas e destilarias) estavam sujeitos a um paradigma subvencionista (Shikida, 1997).

Com a desregulamentação setorial, o sistema passou por grandes transformações institucionais e organizacionais. Como consequência da menor participação do Estado nas atividades ligadas ao setor, os empresários foram impelidos a viabilizar novas formas de acesso aos recursos necessários para os investimentos em modernização agrícola e industrial. Convivendo num ambiente cada vez mais concorrencial, as organizações também passaram a adotar instrumentos de gestão, até então negligenciados por parcela expressiva dos empresários do setor (Vian, 2003).

Nesta análise a agroindústria canavieira se insere num processo de mudança do ambiente institucional e que induz a novas estratégias das organizações privadas e públicas e a mudanças nos custos de transação. Esta contextualização encontra uma importante base teórica e conceitual na abordagem da Nova Economia Institucional (NEI) em face da premissa de que os produtores, a partir do processo de desregulamentação de suas atividades, passaram a adotar características comportamentais aliadas às das transações como forma de efetuar suas operações econômicas e obter ganhos em uma situação de livre concorrência. Isto posto, o objetivo deste artigo é investigar as principais percepções dos dirigentes da agroindústria canavieira no Paraná à guisa da Nova Economia Institucional, frente aos desafios ocasionados pela desregulamentação setorial.

O presente artigo está estruturado em cinco seções, incluída esta introdução. Na segunda seção consta um sucinto referencial teórico, na terceira a metodologia para levantamento dos dados da pesquisa, na quarta seção apresentam-se os resultados e discussão e na quinta seção fazem-se as considerações finais. 


\section{2) REFERENCIAL TEÓRICO: BREVES NOTAS SOBRE A NOVA ECONOMIA INSTITUCIONAL}

A partir da década de 1930 uma série de autores, tais como Coase, Commons, Knight, Barnard e Hayek afirmaram que a teoria neoclássica é uma ferramenta inadequada para analisar e prescrever políticas que induzam ao desenvolvimento das firmas (Azevedo, 1997a; Rocha Júnior, 2004).

Em seu clássico artigo, citado mais de 39.000 vezes (vide scholar.google.com.br), "The Naturenof the firm", Coase (1937) estabeleceu um novo marco no estudo das organizações e que inspirou os avanços para o que se convencionou denominar Nova Economia Institucional (NEI) (Williamson, 1975). A visão central de Coase é de que a firma não seria apenas um espaço para transformação do produto, mas essencialmente um dispositivo para a criação de contratos entre os agentes econômicos envolvidos nas diversas transações a que estariam sujeitos, tais como a contratação de trabalhadores, negociação de preços ou cumprimento de acordos. Na ótica "coasiana" é difícil e dispendioso definir o momento certo de selecionar o trabalhador para determinada tarefa, ou procurar insumos, controlar o desempenho, renegociar preços e proteger segredos num mercado aberto.

Com efeito, a NEI avançou nos estudos da moderna organização industrial, pois apresenta aspectos mais completos e detalhados do ambiente institucional e das variáveis transacionais que caracterizam a organização das firmas e dos mercados. A NEI considera que o papel das instituições pode reduzir o custo das interações entre os agentes, ao restringir as ações humanas, constituindo-se, desse modo, num elemento relevante à eficiência econômica e ao desenvolvimento (Paulillo, 2001). As pesquisas realizadas através dessa abordagem procuram compreender os motivos que levam vários comportamentos e arranjos institucionais emergirem e se adaptarem em resposta aos desafios de ganhos de eficiência, economizando nos custos de realização de transações entre os agentes econômicos. O auto interesse dos agentes poderia provocar uma ação oportunística ao operar em um mundo de racionalidade limitada (Joskow, 1995).

Na visão central de Coase (1937), corroborada por Zylbersztajn (1995), as firmas, como participantes do mercado, incorrem o tempo todo em custos de transação. A necessidade de contratação de mão-de-obra, a negociação de preços e o cumprimento de contratos são exemplos de atividades que causam custos transacionais. As firmas, então, seriam essencialmente um agente 
concebido para criar e gerenciar contratos no longo prazo, resumidamente, as firmas seriam um nexus de contratos, formando arranjos institucionais e regulamentando as transações.

Uma implicação direta da firma como nexus de contratos foi abordada por Williamson $(1975 ; 1985 ; 2012)$ ao apresentar o "homem contratual" no estudo das organizações econômicas. A economia dos custos de transação caracteriza a natureza humana como detentora de racionalidade limitada e oportunismo nas relações contratuais.

Williamson (1985) identifica, além do aspecto comportamental dos agentes em relações contratuais, a presença de três dimensões ligadas diretamente as transações. A primeira é a frequência das transações (ocasionais e recorrentes). Nesse tocante as transações recorrentes terão menor custo de transação, já que a possibilidade de ocorrência de comportamento oportunístico será substituída pelo desenvolvimento de comprometimentos e manutenção da reputação dos agentes. A segunda dimensão nas transações é a incerteza, que não permite a elaboração de contratos completos causando, entre outros, a abertura para comportamentos oportunistas. A teoria sugere que num ambiente de recorrente incerteza as estruturas de governança devem ser mais coordenadas. A terceira dimensão trata da especificidade dos ativos envolvidos na transação. Ativos são específicos se o retorno associado a eles depender da continuidade de uma transação específica. Os custos de transação aumentam na proporcionalidade dos ativos específicos. Admitem-se seis tipos de especificidade: locacional, de capital físico, de capital humano, de ativos dedicados, de marca e temporal (Mondelli; Zylbersztajn, 2008).

Economizar nos custos de transação é a principal finalidade das organizações econômicas. Porém, como as transações diferem em suas necessidades adaptativas (autônomas ou coordenadas), as estruturas de governança diferem em suas capacidades adaptativas, e a adaptação malsucedida compromete a viabilidade e continuidade de qualquer empresa; economizar passa a ser condição sine qua non para a sobrevivência das firmas em mercados concorrenciais (Williamson, 2012).

O arcabouço da Nova Economia Institucional é amplo, porém este estudo concentrará suas investigações no entendimento de algumas das características básicas que sustentam esta parte da teoria econômica, tais como: as instituições, com suas regras formais e informais; as organizações e, em especial, seus empresários, que são os atores da inovação institucional; e sobre as relações entre firmas que não ocorrem por meio dos mercados e sim 
dos contratos.

\section{3) METODOLOGIA}

Para abordar o estudo descrito realizou-se uma pesquisa junto às agroindústrias produtoras de cana-de-açúcar no Paraná. A base de informações usadas para esta finalidade foi o Anuário da Cana 2011. A metodologia empregada foi a de pesquisa de observação direta extensiva, realizada por meio de técnica de interrogação mediante aplicação de questionário. O instrumento de coleta de dados foi constituído por uma série ordenada de perguntas que foram respondidas por escrito, com a presença do entrevistador (Marconi; Lakatos, 1996), sendo utilizada, também, a internet como plataforma de coleta de dados. No caso dos questionários via internet cada respondente foi convidado a participar da pesquisa por meio de um link num website criado para a investigação, e as respostas foram enviadas por meio do google docs. Ainda em relação aos questionários online, estes foram desenvolvidos pelos pesquisadores, porém as formatações das perguntas, visando atender à lógica da pesquisa, foram executadas em conjunto com profissional da área de tecnologia da informação e desenvolvimento de softwares. Quanto às análises dos resultados, estas foram tabuladas e descritas pelos pesquisadores, utilizando, quando necessário, apresentação gráfica dos resultados.

Conforme Chizzotti (2001), o questionário é um conjunto de questões pré-elaboradas de forma sistemática e sequencial dispostas em itens que constituem o tema da pesquisa, com o objetivo de suscitar dos informantes respostas, por meio escrito ou verbal, sobre determinado assunto que os pesquisados têm profusão em opinar ou informar. Portanto, é uma interlocução tecnicamente planejada.

No caso das pesquisas em ciências sociais, muitas dúvidas são concernentes à validade e confiança dos resultados obtidos. Para os problemas de confiabilidade e da validação dos resultados de estudos qualitativos não há soluções simples. Bradley (1993) recomenda o uso de quatro critérios para atenuá-los, a saber: conferir a credibilidade do material investigado; zelar pela fidelidade no processo de transcrição que antecede a análise; considerar os elementos que compõem o contexto; e assegurar a possibilidade de confirmar posteriormente os dados pesquisados. Constata-se em Neves (1996, p. 4) que "cumprir sequenciada e integralmente as fases de 
projeto de pesquisa, coleta de dados, análise e documentação contribuem para tornar mais confiáveis os resultados do estudo qualitativo".

Frise-se que os dados analisados foram obtidos junto aos dirigentes agroindustriais, com participação efetiva em reuniões da Associação de Produtores de Bioenergia do Estado do Paraná (ALCOPAR) como representantes dos grupos privados, do setor produtor de cana, açúcar e etanol, em pesquisa de campo efetuada entre os meses de janeiro/2014 a novembro/2014, bem como respostas online. Os dados obtidos por meio de pesquisa de campo foram transcritos para o formulário eletrônico a fim de obter uma saída uniforme das respostas. Como resultado da pesquisa de campo e das respostas recebidas no link criado para o estudo em questão, obteve-se um total de 8 grupos privados respondentes. De acordo com dados disponíveis no Portal da Cana (2015), os grupos informantes são detentores de 18 unidades em operação no Paraná (60\% das unidades produtivas). Destaque-se que todas as usinas/destilarias dos grupos empresariais informantes da pesquisa possuem autorizações da Agência Nacional do Petróleo (ANP) e do Ministério da Agricultura, Pecuária e Abastecimento (MAPA) para funcionarem no Brasil, podendo também exportar etanol para os Estados Unidos. Três destes grupos possuem unidades que aderiram ao Compromisso Nacional para Aperfeiçoar as Condições de Trabalho na Canade-Açúcar, e três unidades produtoras de etanol do Paraná obtiveram registro completo do Conselho de Qualidade do Ar da Califórnia (CARB), órgão ambiental do estado norte-americano. Os respondentes apresentam conjuntamente $68 \%$ da capacidade de moagem no Paraná.

Em função de critérios definidos previamente, e visando manter o anonimato das empresas e organizações, os resultados foram tabulados e analisados de forma agregada.

\section{4) RESULTADOS E DISCUSSÃO}

O desempenho econômico, na visão neoinstitucionalista de North (1981; 1994), está diretamente ligado às instituições e a sua consequente evolução; em conjunto com a tecnologia empregada, elas determinam os custos de transação e produção. Quanto ao ambiente institucional e especificamente sobre o papel desempenhado pelas regras formais, e que impactam, positivamente e negativamente, no desenvolvimento da organização agroindustrial canavieira no Paraná observa-se, conforme Gráfico 1, que a legislação trabalhista e previdenciária, as políticas setoriais governamentais e a legislação tributária representam os maiores problemas 
para a totalidade dos dirigentes pesquisados, e que se relacionam de forma negativa com o setor. Quanto aos aspectos positivos, a maior parte dos respondentes $75 \%$ (significa 6 respondentes de um total de 8 respondentes) afirma que "nenhuma regra interfere positivamente" no setor agroindustrial canavieiro do Paraná, porém 25\% (significa 2 respondentes de um total de 8 respondentes) dos pesquisados consideram que as "regulamentações setoriais" interferem de modo positivo.

Gráfico 1: Regras formais que interferem no desempenho e/ou desenvolvimento da usina/destilaria

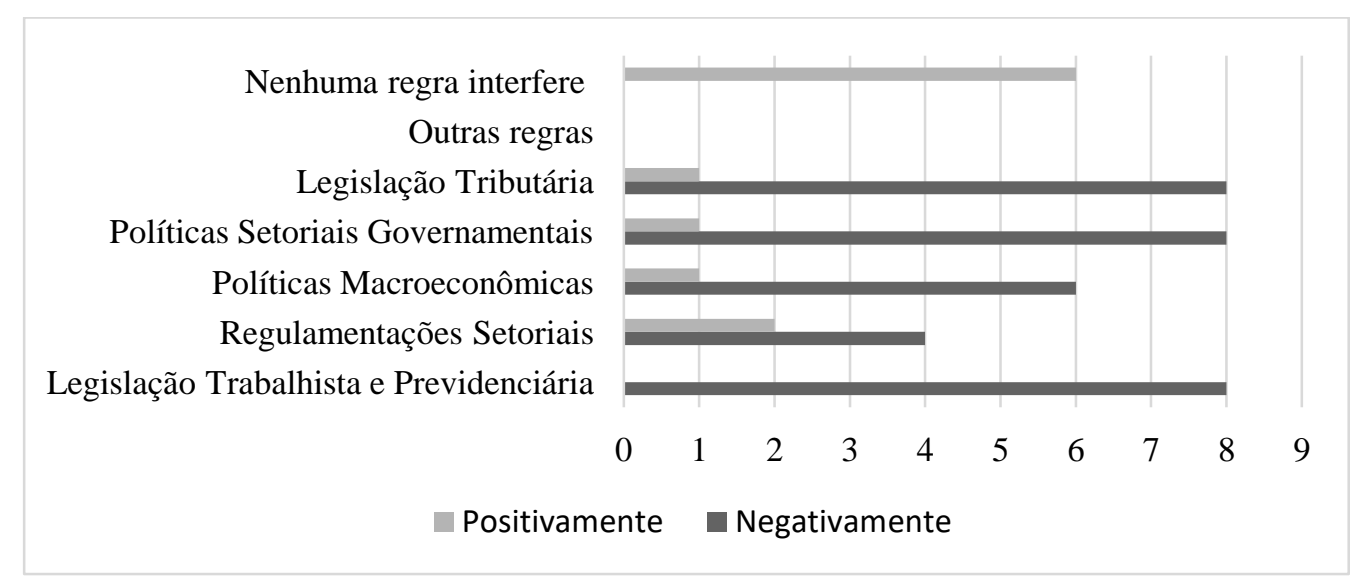

Fonte: Dados da Pesquisa.

Em relação às regras informais (Gráfico 2) as respostas não apontaram nenhum fator determinante, tanto negativamente quanto positivamente, ou seja, na percepção do corpo diretivo das unidades produtoras as regras informais não atuam de modo impactante no desempenho das organizações.

Gráfico 2: Regras informais que interferem no desempenho e/ou desenvolvimento da usina/destilaria

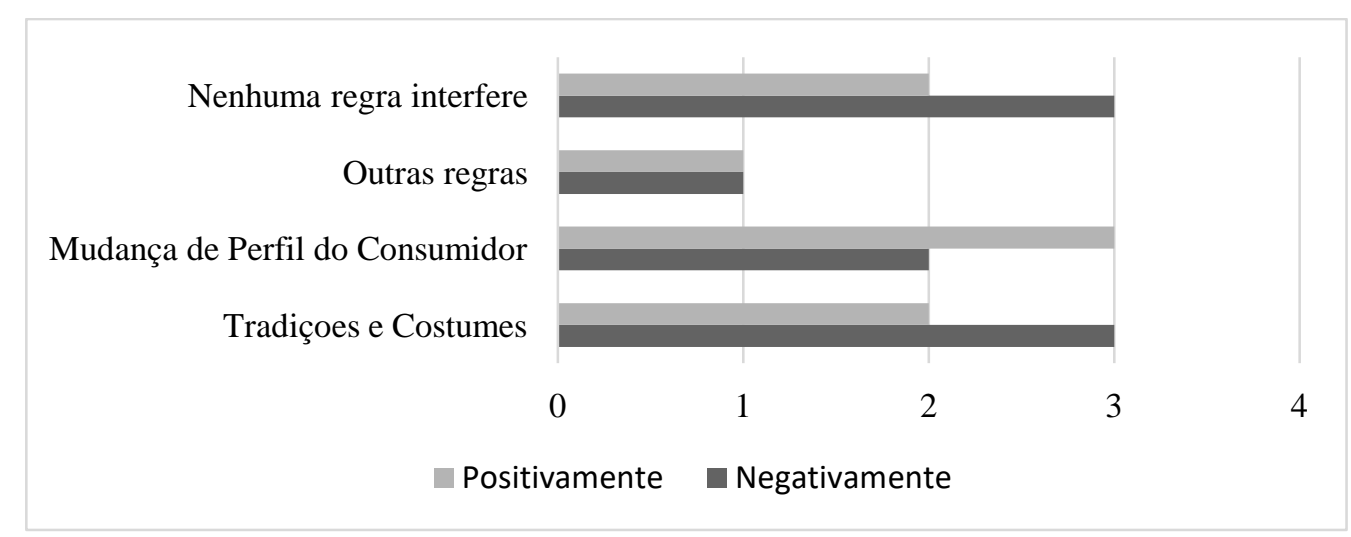

Fonte: Dados da Pesquisa. 
Os dados confirmam a importância sobre a equidade das "regras do jogo" e as percepções individuais que afetam o desempenho das organizações. As instituições devem propiciar aos "jogadores", em determinado momento, não só avaliação e execução contratuais de baixo custo, como também oferecer incentivos que estimulem decisões descentralizadas e mercados efetivamente competitivos. De acordo com North (1994, p. 13), "para que a eficiência seja duradoura, é essencial haver instituições econômica e politicamente flexíveis, que se adaptem às novas oportunidades". No caso desta pesquisa, pode-se concluir no momento da aplicação do questionário que a opinião dos dirigentes das empresas sucroalcooleiras no Paraná refletia a percepção geral do setor em relação às "regras do jogo" adotadas pelo Estado, principalmente no mercado de etanol que, até então, era altamente regulado pelo governo que controlava os preços da gasolina, apesar das oscilações internacionais do barril de petróleo.

As organizações são compostas por grupos de indivíduos dedicados a alguma atividade executada com determinado fim. Evidenciando este aspecto e a importância da atuação coletiva em entidades representativas no desenvolvimento setorial, todas as unidades respondentes estão vinculadas a ALCOPAR.

O Gráfico 3 apresenta as formas de parceria comumente utilizadas no setor que visam melhorias nos processos e produtos.

Gráfico 3: Formas de parcerias no desenvolvimento dos processos/produtos

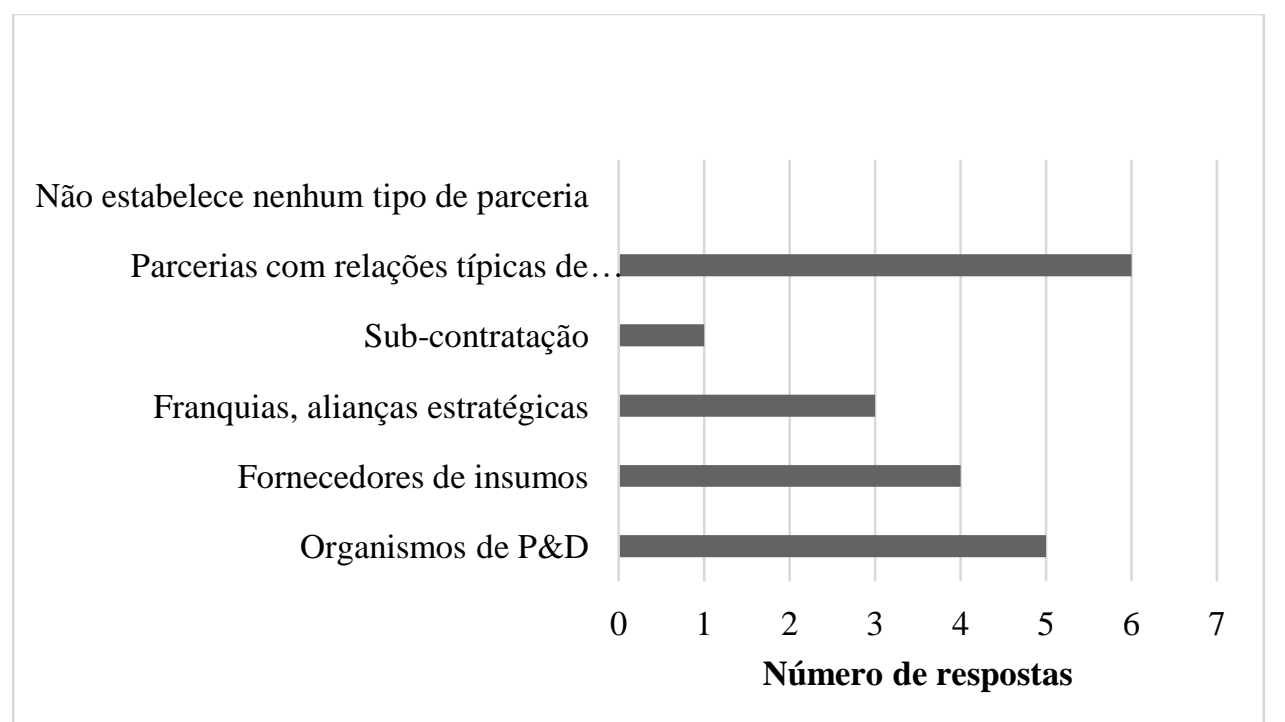

Fonte: Dados da Pesquisa. 
Os resultados mais significativos foram: $75 \%$ apontaram "as parcerias como relações típicas de produção" e 63\% assinalaram "organismos de pesquisa e desenvolvimento (P\&D)". Outra observação a destacar neste item é que todas as unidades estabelecem algum tipo de parceria. Os resultados mostram também que os gestores tendem a empregar maiores níveis de formas relacionais com os seus contratos, tornando-se cada vez mais personalizados, e empregam personalização elevada conforme se desenvolvem maiores níveis de governança contratual. Estes pontos tornamse relevantes para as transformações do setor agroindustrial canavieiro que se integrou a indústria, porque os mecanismos de governança acabam determinando a dinâmica dos diferentes encadeamentos, seja em termos organizacionais ou tecnológicos.

Agricultores também se organizam horizontalmente na forma de relações contratuais ou acordos informais de produção, seja como forma de ganhar em economias de escala, economias de rede, adicionar valor de forma seletiva, ou para ampliar o potencial de coordenação com a indústria processadora, ocasionando incentivos para a integração horizontal que amplia o valor da organização (Zylbersztajn, 1995). Este aspecto é evidenciado pelos informantes do setor no Paraná que mostram que a matéria-prima nas agroindústrias provém na quase totalidade das unidades (88\%), ou seja, de produção própria, caracterizando a integração horizontal como fator determinante neste setor agroindustrial (Gráfico 4).

Gráfico 4: Formas de aquisição de matéria-prima na agroindústria canavieira no Paraná

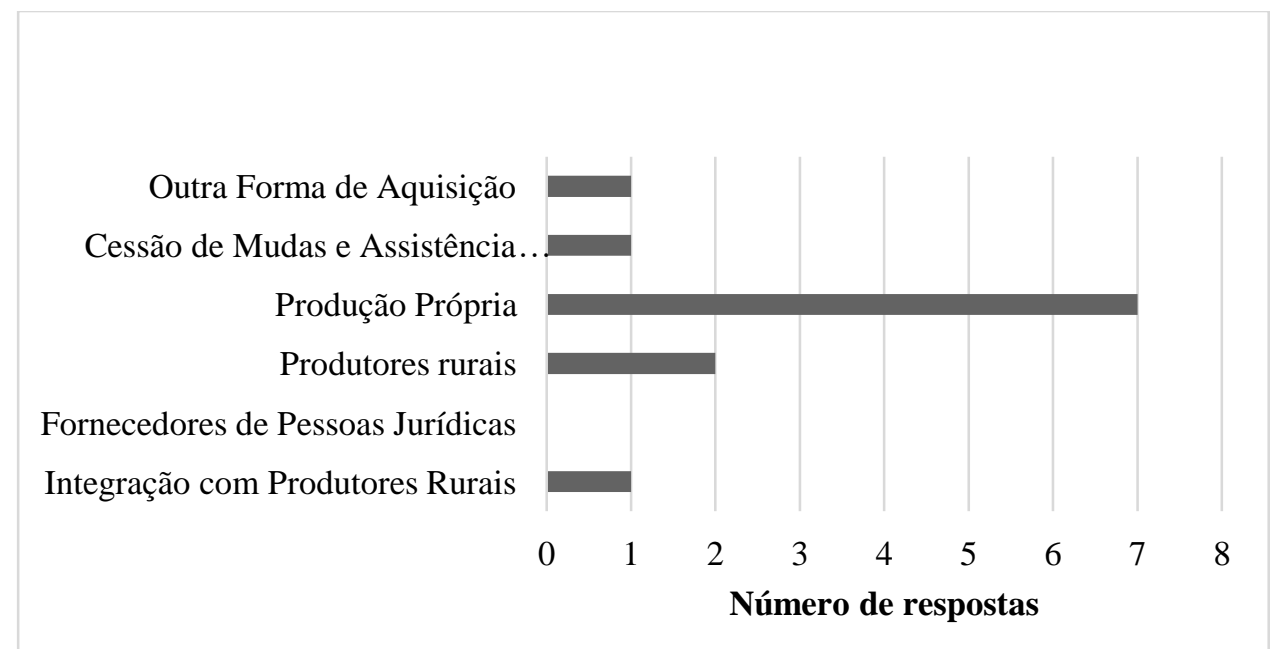

Fonte: Dados da Pesquisa. 
Considerando que são os indivíduos que arquitetam as organizações e que não existem regras fixas para o desenho das organizações, Zylbersztajn (1995) afirma que é preciso identificar quais as variáveis que determinam as formas e as relações entre as organizações. A relação do sistema agroindustrial canavieiro com o setor de insumos, produção, industrialização e distribuição se dá, entre outras formas, via relações contratuais. Estas relações terão um papel preponderante no grau de competividade das organizações agroindustriais canavieiras, podendo determinar seu crescimento, sobrevivência ou extinção do mercado. Na visão da firma como um nexus de contrato, na atuação do "homem contratual" de Williamson (1985), nos comportamentos dos agentes por Azevedo (1997b) e nas dimensões das transações tratadas por Mondelli e Zylbersztajn (2008), é que se inserem as próximas indagações da pesquisa com os dirigentes da agroindústria canavieira no Paraná para captar a importância da NEI, especificamente na formalização de contratos entre os agentes. Constata-se que neste setor no Paraná, a priori, também é suscetível a quebras contratuais pelo fornecedor, que são motivadas essencialmente pela "concorrência com outros produtos" (63\%) (Gráfico 5).

Gráfico 5: Motivações para quebras contratuais

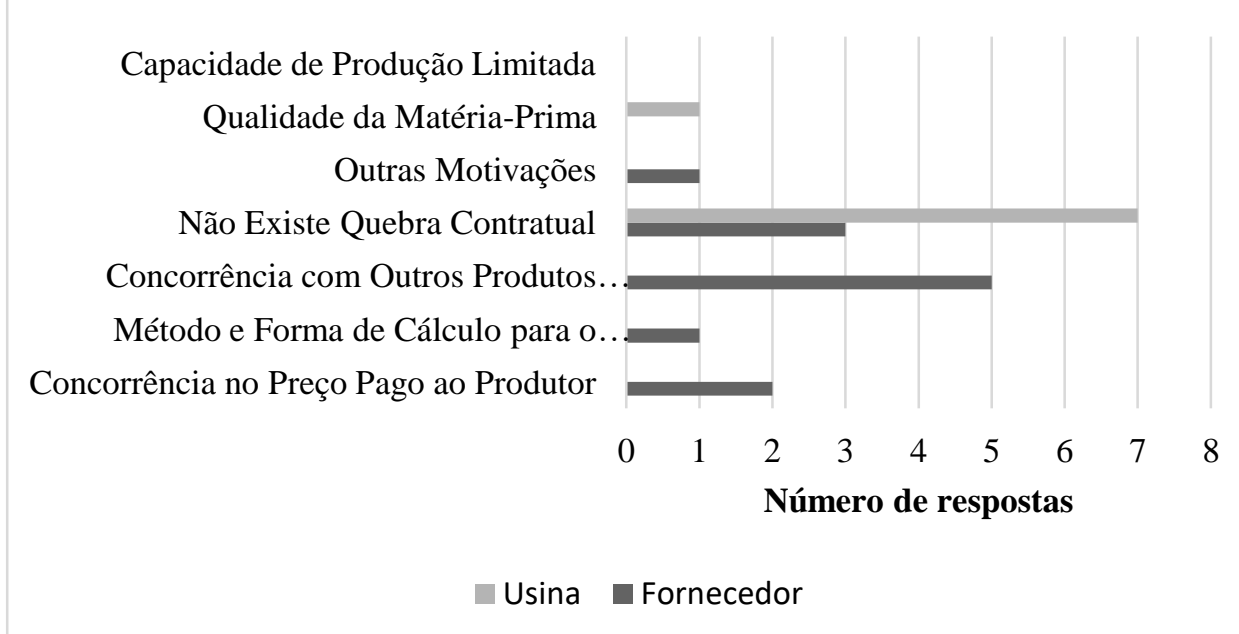

Fonte: Dados da Pesquisa.

No tocante as quebras contratuais por parte das usinas/destilarias, a grande maioria (88\%) afirma que "não há quebras contratuais por parte da empresa" e quando há somente acontece devido à "qualidade da matériaprima" (13\%). Em existindo quebras contratuais, os agentes envolvidos na 
transação tentam se resguardar ou amenizar o comportamento oportunístico, aplicando penalidades ao descumprimento de cláusulas previamente definidas. A punição mais citada pelos respondentes, em caso de quebra contratual, é a pecuniária, como por exemplo: "a indenização dos valores gastos pela usina/destilaria, como eventualmente, fornecimento de mudas e serviços de plantio", reforçando os contratos de parceria da cana que é destinada a industrialização. Ainda em relação aos contratos, nota-se que as empresas pesquisadas possuem, em $88 \%$ dos casos respondidos, na estrutura organizacional uma área ou processo responsável pelo desenho, estruturação, monitoramento e garantia da implementação dos contratos da usina/destilaria, e em apenas um grupo respondente tal situação não ocorre.

Para finalizar a abordagem relacionada aos contratos, os gastos com custas judiciais referentes aos contratos malsucedidos (causas perdidas, atrasos, erros ou omissões), não existiram (50\%) ou foram baixos (50\%). Diante dessa informação, e das demais mencionadas, conclui-se que, dada a baixa incidência de quebras contratuais, os pesquisados não consideram "na formação de custos de produção de açúcar e/ou etanol a provisão de custos para o gerenciamento de contratos ou causas judiciais" (63\%), as "transações com produtores de cana-de-açúcar já atuantes (tradicionais) na usina/destilaria asseguram menor risco nos contratos" (75\%), e "não existe algum diferencial de exigência de salvaguardas contratuais de fornecedores atuantes comparados aos de terceiros ou novos fornecedores" (88\%).

Numa transação econômica sobressaem-se algumas características humanas, e no campo da Teoria dos Custos de Transação (TCT) se manifestam, especificamente, a racionalidade limitada e o oportunismo. Os agentes pretendem ser racionais, de forma maximizadora, porém só conseguem parcialmente. O Gráfico 5 mostra que a maior parte dos agentes pesquisados não considera adotar comportamento oportunístico, tendo em vista afirmarem que não há quebras contratuais por parte da empresa e que o oportunismo se manifestaria em maior grau ao fornecedor de matéria-prima. Com esta argumentação por parte dos informantes, verifica-se a visão de Coase (1937) que descreve a firma como um sistema de relações que surge quando a alocação dos recursos depende de um empresário. Resumindo, os agentes são racionais, mesmo que limitadamente, ou seja, utilizam da melhor forma possível os meios para alcance de seus objetivos. Dessa forma, os agentes constroem estruturas de governança para lidar com a incompletude dos contratos. 
Além dessas características elencadas, os dados relatados até o momento são consistentes e confirmam empiricamente a noção de complementaridade entre os contratos e a governança contratual, isto porque, de acordo com os respondentes, as transações com produtores tradicionais apresentam menor risco contratual, e a lógica da governança contratual apregoa que o sucesso de contratação no passado induz ao maior sucesso no presente. Outra característica que reforça esta abordagem é que $88 \%$ dos respondentes relatam a existência de uma área específica para o gerenciamento de contratos no estabelecimento, de onde se abstrai outra lógica da governança relacional que afirma que contratos claros e articulados limitam o domínio do comportamento oportunista. A governança contratual complementa os limites de adaptação dos contratos, orientando a resolução de conflitos de uma maneira que ambas as partes estabeleçam confiança e resultados mutuamente aceitáveis, promovendo, assim, a continuidade de intercâmbio.

Os próximos resultados da pesquisa reforçam os estudos das organizações descritos por North (1994, p. 13) que afirmam que os mercados eficientes necessitam de avaliação e execução contratuais caracterizadas em "bases permanentes". Uma implicação desse tratamento dado por North (1994) é que "bases permanentes" não coadunam com a incerteza. As organizações, assim como seus agentes, procurarão minimizar os efeitos causados por um ambiente incerto por meio de uma maior liberdade de ações. No caso da pesquisa isto é confirmado pelas respostas que se seguem. No que tange a origem dos "recursos destinados à modernização, pesquisas, etc.", a quase totalidade dos grupos respondentes (7 no total) afirmou ser oriundo de "recursos próprios". A segunda fonte mais citada $(25 \%)$ foi "recursos de financiamentos de agentes privados", e para apenas um dos grupos participantes da pesquisa $(13 \%)$ a origem vem comumente de "recursos de financiamentos oficiais". Isto demonstra uma baixa dependência de recursos financeiros de terceiros para desenvolvimento da atividade agroindustrial da cana no Estado do Paraná.

Passados 25 anos do processo de desregulamentação do setor açúcar e etanol, ou seja, menos intervencionismo do Estado, as perspectivas das agroindústrias canavieiras no Paraná no tocante a produção sucroalcooleira "melhoraram", isto segundo opinião de 5 grupos respondentes $(62 \%)$ ou "não se alteraram" (3 grupos ou 38\%). O resultado revela que, dentre os pesquisados, todos, de alguma forma, não consideram a volta da intervenção governamental uma solução para os problemas relacionados à produção. 


\section{5) CONSIDERAÇÕES FINAIS}

Este artigo investigou as principais percepções dos dirigentes da agroindústria canavieira no Paraná à guisa da Nova Economia Institucional, frente aos desafios ocasionados pela desregulamentação setorial.

Como principais resultados, em relação aos fundamentos da NEI na ótica diretiva da agroindústria canavieira no Paraná, os dados confirmaram uma maior relevância das regras formais na percepção individual dos informantes que afetam o desempenho das organizações. As regras informais, na opinião dos respondentes, não impactam no desempenho organizacional. Outro tópico relatado pelos informantes é que grande parte da matéria-prima destinada ao processo produtivo na unidade é oriunda de áreas pertencentes à usina/destilaria ou arrendadas para este fim, evidenciando-se os contratos e coordenação vertical no setor.

Nos aspectos relacionados às relações contratuais constatam-se, de acordo com os respondentes, os seguintes aspectos: i) que a punição para quebra contratual aplica-se, na maioria das vezes, ao fornecedor de insumos ou matéria-prima (63\% dos respondentes); ii) a importância dos contratos na cadeia, tendo em vista que $88 \%$ dos pesquisados admitem existir uma área ou processo organizacional responsável pelo desenho, estruturação, monitoramento e garantia de implementação de contratos; iii) para $63 \%$ dos respondentes na formação dos custos dos produtos não são considerados os custos de gerenciamento de contratos ou causas judiciais; iv) os produtores tradicionais apresentam menor risco contratual, é o que opinam $75 \%$ dos informantes; e v) não há exigências de salvaguardas para novos contratados (88\% dos respondentes). Ainda em relação ao tópico, a pesquisa aponta que os contratos e a governança contratual nessa atividade apresentam características de complementaridade.

Concluindo a análise da NEI, os dados da investigação salientam que os recursos próprios são os mais utilizados para pesquisa e modernização e que as perspectivas das usinas e destilarias na produção de etanol e açúcar melhoraram no período pós-desregulamentação setorial. Estas situações descritas reforçam a busca pela diminuição da incerteza desses dirigentes.

Este artigo seguiu um determinado rumo metodológico num contexto de outras inclinações possíveis, contudo, sugere-se que outros trabalhos possam aprofundar o conhecimento sobre a dinâmica da agroindústria canavieira pós-desregulamentação, contribuindo para o enriquecimento do debate acerca deste setor que é importante tanto para a questão de segurança 
alimentar (via produção do açúcar) como para a segurança energética nacional (via produção de etanol e cogeração de energia elétrica a partir da queima do bagaço da cana). 


\section{REFERÊNCIAS}

Anuário da Cana 2011. (2011) - Brazilian sugar and ethanol guide. Ribeirão Preto: ProCana Brasil, 2011. 434 p.

Azevedo, P. F. de. (1997a.) - Antecedentes. In: Farina, E. M. M. Q.; Azevedo, P. F. de; Saes, M. S. M. (Eds.).Competitividade: mercado, estado e organizações. São Paulo: Singular, p. 3352.

Azevedo, P. F. de. (1997b.) - Economia dos custos de transação. In: Farina, E. M. M. Q.; Azevedo, P. F. de; Saes, M. S. M. (Eds.). Competitividade: mercado, estado e organizações. São Paulo: Singular, p. 71-111.

Bradley, J. (1993) - Methodological issues and practices in qualitative research. Library Quarterly, v. 63, n. 4, p. 431-449.

Chizzotti, A. (2001) -Pesquisa em ciências humanas e sociais. São Paulo: Cortez, 164 p.

Coase, R. (1937) - The nature of the firm. Economica, v. 4, n. 16, p. 396-405.

Dahmer-Felício, V. S. (2011) - Avaliação de contratos na agroindústria canavieira paranaense utilizando a Nova Economia Institucional e Análise Fatorial de Correspondência. Dissertação de Mestrado, Toledo, Universidade Estadual do Oeste do Paraná.95 p.

Joskow, P. L. (1995) - The new institutional economics: alternative approaches. Journal of Institutional and Theoretical Economics (JITE), v.151, n.1, p.248-259.

Kaefer, G. T.; Shikida, P. F. A. (2000) - A gênese da cana-de-açúcar no Paraná e seu desenvolvimento recente. Tempo da Ciência, v.7, n.13, p.93-104.

Marconi, M. A.; Lakatos, E. M. (1996) - Técnicas de pesquisa. São Paulo: Atlas.

Mondelli, M.; Zylbersztajn, D.(2008) - Determinantes dos arranjos contratuais: o caso da transação produtor-processador de carne bovina no Uruguai. Revista de Economia e Sociologia Rural, v. 46, n. 3, p. 831-868.

Neves, J. L.(1996) - Pesquisa qualitativa: características, usos e possibilidades. Cadernos de Pesquisa em Administração, São Paulo, v. 1, n. 3, p. 1-5.

North, D. C. (1994) -Custos de transação, instituições e desempenho econômico. Rio de Janeiro: Instituto Liberal, 38 p.

North, D. C. (1981) - Structure and change in economic history. New York: W. W. Norton \& Company, $228 \mathrm{p}$.

Paulillo, L. F. (2001) - Sobre o desenvolvimento da agricultura brasileira: concepções clássicas e recentes. In: Batalha, M. O. (Coord.). Gestão agroindustrial. 2. ed. São Paulo: Atlas,v. 1, p. 656-690.

Portal da Cana 2015. (2015) - Dados estatísticos do setor sucroenergético. Disponível em: <www.novacana.com/usinas-brasil/sul/parana/>. 
Rocha Júnior, W. F. da.(2004) - A Nova Economia Institucional revisitada. Revista de Economia e Administração, v. 3, n. 4, p. 301-319.

Secretaria da Agricultura e do Abastecimento do Estado do Paraná (SEAB). (2011) - A situação e tendências do setor sucroalcooleiro. Curitiba: DERAL.

Shikida, P. F. A. (1997) -A evolução diferenciada da agroindústria canavieira no Brasil de 1975 a 1995.Tese de Doutorado,Piracicaba, Universidade de São Paulo. 191 p.

Tranin, $\quad$ M. $\quad$ R. (2014) -Bioenergia. Disponível em <http://smartenergy.org.br/2014/images/palestras/08maio_tarde/1_Etanol_Miguel_Tranin.pdf>.

União da Indústria de Cana-de-Açúcar (UNICA). (2015) -Unicadata. Disponível em <http://www.unicadata.com.br>.

Vian, C. E. de F. (2003)Agroindústria canavieira: estratégias competitivas e modernização. Campinas: Átomo, 217 p.

Williamson, O. (1985) - The economic institutions of capitalism: firms, markets, relational contracting. New York: The Free Press. 450 p.

Williamson, O. E. (2012) -Transaction Cost Economics: what are the questions? Disponívelem: <http://businessinnovation.berkeley.edu/ WilliamsonSeminar/williamson040512.pdf>.

Williamson, O. (1975) -Markets and hierarchies. New York: Free Press, 286 p.

Zylbersztajn, D.(1995) - Estruturas de governança e coordenação do agribusiness: uma aplicação da Nova Economia das Instituições. Tese Livre-Docência,São Paulo, Universidade de São Paulo, 238 p 